\title{
Forecasting of boro rice production in Bangladesh: An ARIMA approach
}

\author{
N. M. F. Rahman \\ Department of BBA, Mirpur University College, Dhaka
}

\begin{abstract}
The study was undertaken to examine the best fitted ARIMA model that could be used to make efficient forecast boro rice production in Bangladesh from 2008-09 to 2012-13. It appeared from the study that local, modern and total boro time series are 1 st order homogenous stationary. It is found from the study that the ARIMA $(0,1,0)$ ARIMA $(0,1,3)$ and ARIMA $(0,1,2)$ are the best for local, modern and total boro rice production respectively. It is observed from the analysis that short term forecasts are more efficient for ARIMA models. The production uncertainty of boro rice can be minimizing if production can be forecasted well and necessary steps can be taken against losses. The government and producer as well use ARIMA methods to forecast future production more accurately in the short run.
\end{abstract}

Keywords: Production, ARIMA model, Forecasting.

\section{Introduction}

Agro-based developing country like Bangladesh is striving hard for rapid development of its economy. The economic development of the country is mainly based on agriculture. The contribution of agriculture sector in GDP is 20.87 percent (BER, 2008). In the agriculture sector, the crop sub-sector dominates with 14.32 percent in GDP of which rice alone contributes about 53 percent. In Bangladesh although 63 percent of the labour force is directly engaged in agriculture and 78 percent of total crop is devoted to rice production, the country has still a chronic shortage of food-grain (BBS.2003). Boro - a Bengali term originated from the Sanskrit word 'BOROB'. It refers to a special cultivation of rice in low land pockets during November-May; taking advantage of the residual water in the field after harvest of Kharif crop, longer moisture retentivity of the soil and surface water stored in the near by ditches (Singh et al 2003a). Thakur et al. (2003) reported boro in Shivapuran as one of the offerings to the God. In Bangladesh rice is grown in three distinct seasons; boro (January to June), aus (April to August), and amon (August to December). Modern rice varieties were introduced for the boro and aus seasons in 1967 and for the amon seasons in 1970 (Hossain et al. 1994). In Bangladesh boro rice occupied nearly $35 \%$ of the 10.80 million ha of rice harvested area, and contributed $50 \%$ of the 38.7 million tons of rice produced in 2001/2002. The yield in 2001/2002 was 4.9 ton/ha (Singh et al 2003b).

For future planning it is necessary to evaluate the growth pattern of boro rice production that is achieved at the time in the country as a whole and also in the different varieties of the country. To reveal the growth pattern and to make the best forecast of boro production in Bangladesh appropriate time series model that can be able to describe the observed data successfully are necessary.

For prediction purpose one or both of two types of models, usually known as structural regression models and time series models are often used in practice. The use of structural regression models requires information about the factors affecting the time series. On the other hand, time series analysis, especially Box-Jenkin type ARIMA models, let the data speak for themselves i.e. the future movements of a time series are determined using its own present and past values (Box and Jenkins, 1978). Among the stochastic time series models ARIMA types are very powerful and popular as they can successfully describe the observed data and can make forecast with minimum forecast error. These types of models are very difficult to identify and estimate. They are also expensive, time consuming and possesses a complex model building mechanism. So far we know few works have been undertaken for forecasting boro rice production in Bangladesh using ARIMA models. The objective of the study is to develop appropriate ARIMA models for the time series of local, modern and total boro rice production in Bangladesh and to make five year forecasts for all the time series with appropriate prediction interval. 


\section{Material and Methods}

To achieve the stipulated objectives, the present study has been carried out on the basis of local, modern and total boro rice production data pertaining the period 1967-68 to 2007-08, which were collected from secondary (BBS various issues) source. The time series data of local, modern and total boro rice production were modeled by Box-Jenkins type stochastic autoregressive integrated moving average (ARIMA) process. The Box-Jenkins type ARIMA process (Box and Jenkins, 1978) can be defined as $\phi(B)\left(\Delta^{d} y_{t}-\mu\right)=\theta(B) \varepsilon_{t}$, Here, $y_{t}$ denotes local, modern and total boro rice production million metric tons, $\mu$ is the mean of $\Delta^{d} Y_{t}, \phi(B)=1-\phi_{1} B-\cdots-\phi_{p} B^{p}, \theta(B)=1-\theta_{1} B-\cdots-\theta_{q} B^{q}$, $\theta_{i}$ denotes the ith moving average parameter, $\phi_{i}$ denotes the ith autoregressive parameter, $p, q$ and $d$ denote the autoregressive, moving average and difference order of the process respectively, $\Delta$ and $B$ denote the difference and back-shift operators respectively.

The estimation methodology of the above model consists of three steps, namely, identification, estimation of parameters and diagnostic checking. The identification step involves the use of the techniques for determining the value of $p, d$ and $q$. Here, these values are determined by using autocorrelation and partial autocorrelation functions (ACF and PACF) and Augmented Dickey-Fuller (ADF) test. The model used for ADF is $y-y_{t-1}=\alpha+\beta t+(\rho-1) y_{t-1+\lambda \Delta y_{t-1}}$ (Pindyck and Rubinfeld, 1991, p.461). The second step is to estimate the parameters of the model. Here, the method of maximum likelihood is used for this purpose. The third step is to check whether the chosen model fits the data reasonably well. For this reason the residuals are examined to find out if they are white noise. To test if the residuals are white noise the ACF of residuals and the Ljung and Box (1978) statistic are used. In case of two or more competing models passing the diagnostic checks the best fitted model is selected using the following criteria multiple $\mathrm{R}^{2}$, Adjusted $\overline{R^{2}}$, Root mean squared error (RMSE), Akaike Information Criterion (AIC), Bayesian Information (BIC), Mean absolute error (MAE) and Mean absolute proportion percent error (MAPPE).

\section{Results and Discussion}

\section{Stationarity checking using ACF}

Auto correlation function is a very constructive tool to find out whether a time series is stationary or not. Both ACF and PACF are used to determine auto-regression and moving average orders of the models. ACF and PACF of our three time series of local, modern and total Boro rice production are constructed. All the graphs represent that autocorrelations taper of very slowly indicating that all the series are nonstationary (Fig. 1, Fig. 3 and Fig. 5. Now it is needed to take 1st-difference of all the time series and construct autocorrelation functions to see if they are stationary or not. The autocorrelation functions of $1 \mathrm{st}$ differenced time series of local, modern and total boro rice production are presented in Fig. 2, Fig. 4 and Fig. 6 respectively. The 1st differenced time series shows stationarity, as the autocorrelation declines faster than the auto correlation of undifferenced series.

Now it is clear that ACFs of all the $1^{\text {st }}$-differenced series decline rapidly. So, it is revealed that local, modern and total Boro time series are stationary of order one. Before taking decision about stationarity of the series, the study need to carry out the formal ADF test of stationarity.

\section{Stationarity Checking using ADF}

A part from the graphical methods of using ACF for determining stationarity of a time series, a very popular formal method of determining stationarity is the Augmented Dickey-Fuller test. Here, these tests done for all the time series. The estimates of necessary parameters and related statistics for the time series of local, modern and total Boro rice production are presented in Table 1. 
Table 1. ADF test of stationarity of local, modern and total Boro rice production in Bangladesh

\begin{tabular}{|c|c|c|c|c|c|c|c|c|c|c|}
\hline Area & Model & $\alpha$ & $\beta$ & $(\rho-1)$ & $\lambda$ & RSS & DF & DW & $\mathrm{F}$ & $F_{05,41}$ \\
\hline \multirow[t]{4}{*}{ Local } & Unrestricted & 231781.52 & -3732.79 & -.35 & -.18 & 207539906444.8 & 35 & 2.28 & 5.20 & \multirow{12}{*}{6.95} \\
\hline & S. Error & 104734.65 & 2092.78 & .12 & .142 & & & & & \\
\hline & Restricted & -28029.58 & & & -.34 & 265918308058.3 & 37 & 2.14 & & \\
\hline & S. Error & 13760.84 & & & .14 & & & & & \\
\hline \multirow[t]{4}{*}{ Modern } & Unrestricted & -432072.40 & 126461.56 & -.40 & -.16 & 893496.9431 & 35 & 1.24 & \multirow[t]{4}{*}{0.14} & \\
\hline & S. Error & 751854.11 & 74148.54 & .20 & .58 & & & & & \\
\hline & Restricted & 331476.08 & & & -.56 & 900047.9361 & 37 & 1.11 & & \\
\hline & S. Error & 329235.36 & & & .53 & & & & & \\
\hline \multirow[t]{4}{*}{ Total } & Unrestricted & -104028.03 & 123636.05 & -.40 & -.19 & 8.321740607 & 35 & 1.24 & \multirow[t]{4}{*}{2.27} & \\
\hline & S. Error & 619698.91 & 70187.98 & .20 & .53 & & & & & \\
\hline & Restricted & 305855.65 & & & -.55 & 9.344842050 & 37 & 1.11 & & \\
\hline & S. Error & 308165.10 & & & .49 & & & & & \\
\hline
\end{tabular}

The analysis exposed that the hypothesis of random walk that underlying process of generating the time series is non-stationary can not be rejected, as the related $\mathrm{F}$ statistics is insignificant at $5 \%$ level. So, all the undifferenced time series are non stationary and they must be $1^{\text {st }}$-differenced to see if $1^{\text {st }}$-differenced are nonstationary.

To perform the ADF test for the $1^{\text {st }}$-differenced time series of local, modern and total Boro rice production essential analysis are presented in Table 2. A further, the analysis shows that local, modern and total Boro rice production, the $1^{\text {st }}$-differenced time series are stationary as the $\mathrm{F}$ statistics are significance at $5 \%$ level. From the ACFs and ADF test, we can take decision that local, modern and total boro times series are stationary of order one.

Table 2. ADF test of stationarity of local, modern and total Boro rice $1^{\text {st }}$ different production

\begin{tabular}{|c|c|c|c|c|c|c|c|c|c|c|}
\hline Area & Model & $\alpha$ & $\beta$ & $(\rho-1)$ & $\lambda$ & RSS & DF & DW & $\mathrm{F}$ & $\mathrm{F}_{05,40}$ \\
\hline \multirow{4}{*}{ Local } & Unrestricted & -80221.55 & 2034.03 & -1.62 & .14 & 241838851693.3 & 34 & 1.99 & \multirow{4}{*}{18.88} & \multirow{12}{*}{7.06} \\
\hline & S.Error & 33457.13 & 1286.06 & .27 & .16 & & & & & \\
\hline & Restricted & -4958.75 & & & -.62 & 495513056044.8 & 36 & 2.65 & & \\
\hline & S.Error & 19057.17 & & & .12 & & & & & \\
\hline \multirow{4}{*}{ Modern } & Unrestricted & 574009.50 & -23919.94 & -.74 & -.72 & 9532666.779 & 34 & 1.14 & \multirow{4}{*}{16.10} & \\
\hline & S.Error & 620729.48 & 28754.18 & .83 & .60 & & & & & \\
\hline & Restricted & -233366.83 & & & -1.13 & 1003763.5609 & 36 & 1.12 & & \\
\hline & S.Error & 275558.52 & & & .43 & & & & & \\
\hline \multirow{4}{*}{ Total } & Unrestricted & 517613.78 & -22303.94 & -.72 & -.66 & 4291737.1606 & 34 & 1.15 & \multirow{4}{*}{19.80} & \\
\hline & S.Error & 601496.885 & 28035.957 & .83 & .55 & & & & & \\
\hline & Restricted & -232326.99 & & & -1.04 & 9012506.665 & 36 & 1.15 & & \\
\hline & S.Error & 265956.38 & & & .36 & & & & & \\
\hline
\end{tabular}

\section{Modeling time series of local boro rice production}

For selecting ARIMA model for local boro rice production series a routine test of identification applied before using Box-Jenkins methodology. Figure 1 represents the ACF and PACF plots of local boro rice production series at their level up to 16 lags. From this figure, the facts stand out that at the beginning ACF has five significant spikes and PACF has only one significant spike. On the other hand, the ACF plots and PACF plots in the Fig. 2 is showing a different configuration. In this figure, the ACF shows no significant auto-correlation at any lag. It is also evident from the Box-Ljung statistic presented on the top of ACF that all the differenced values are within the $95 \%$ confidence limit. This implies that the series is non-stationary at their level and stationary at first difference. Moreover, the residuals are uncorrelated. Augmented Dickey-Fuller unit root tests are showing the stationarity position of this series at same order of difference. 


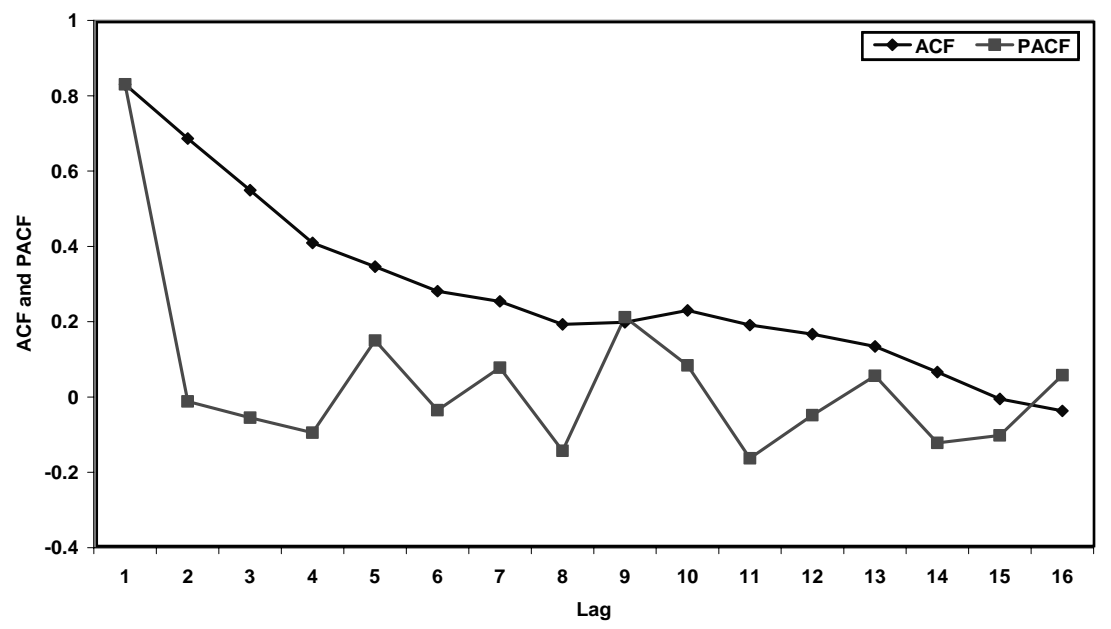

Fig. 1. Undifferenced local boro rice production in Bangladesh

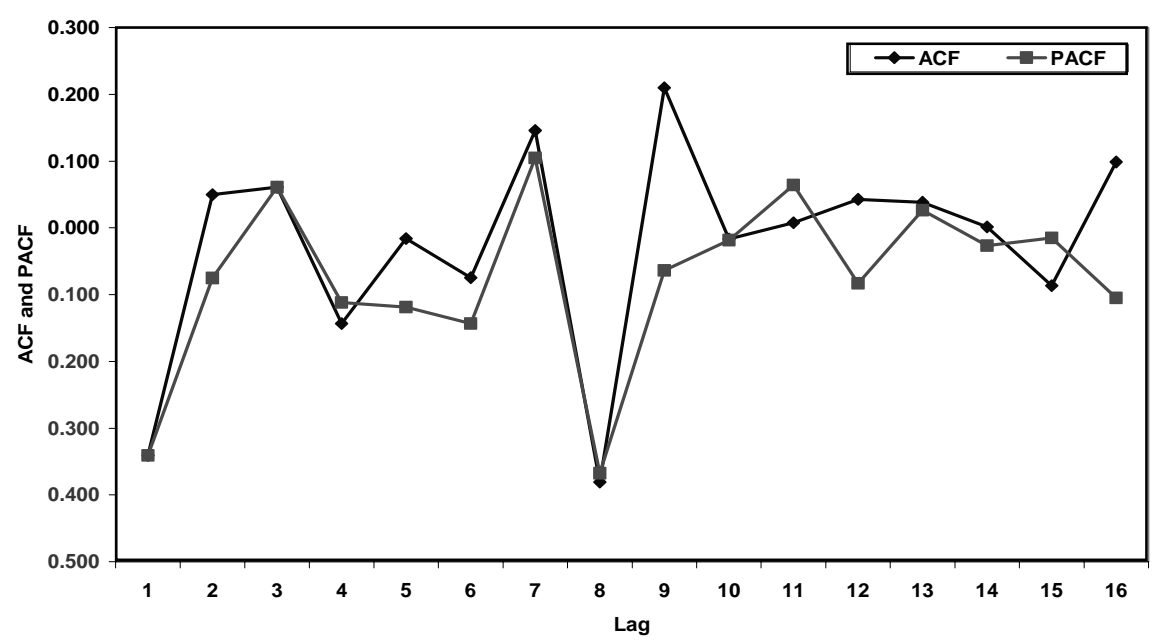

Fig. 2. 1st-differenced local boro rice production in Bangladesh

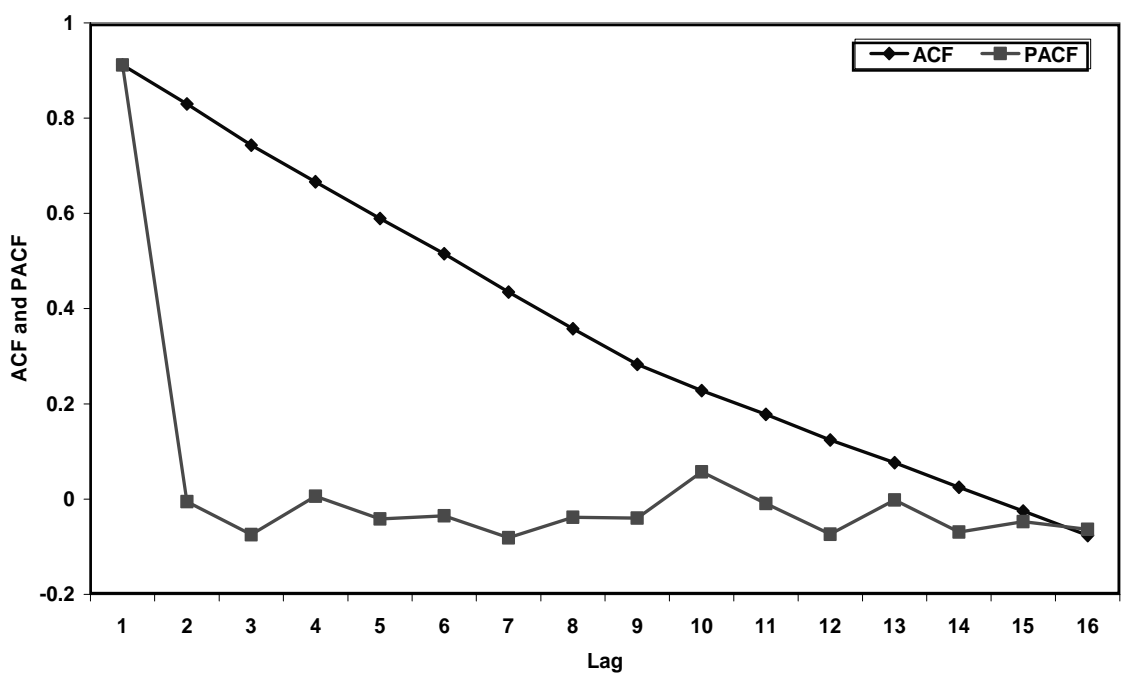

Fig. 3. Undifferenced modern boro rice production in Bangladesh 


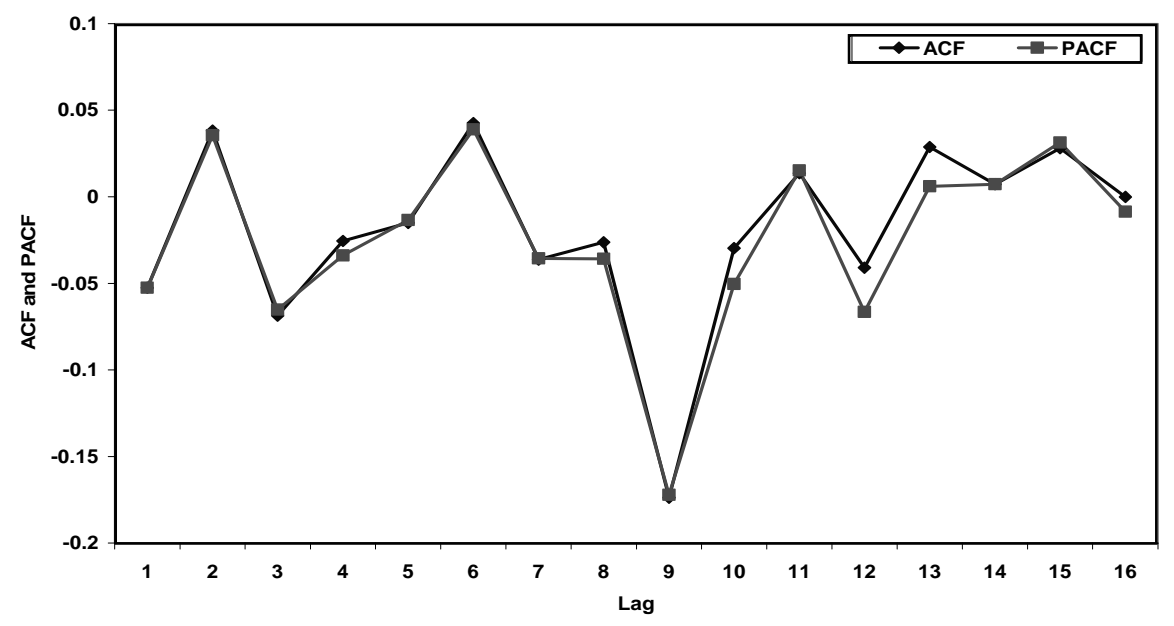

Fig. 4. 1st-differenced modern boro rice production in Bangladesh

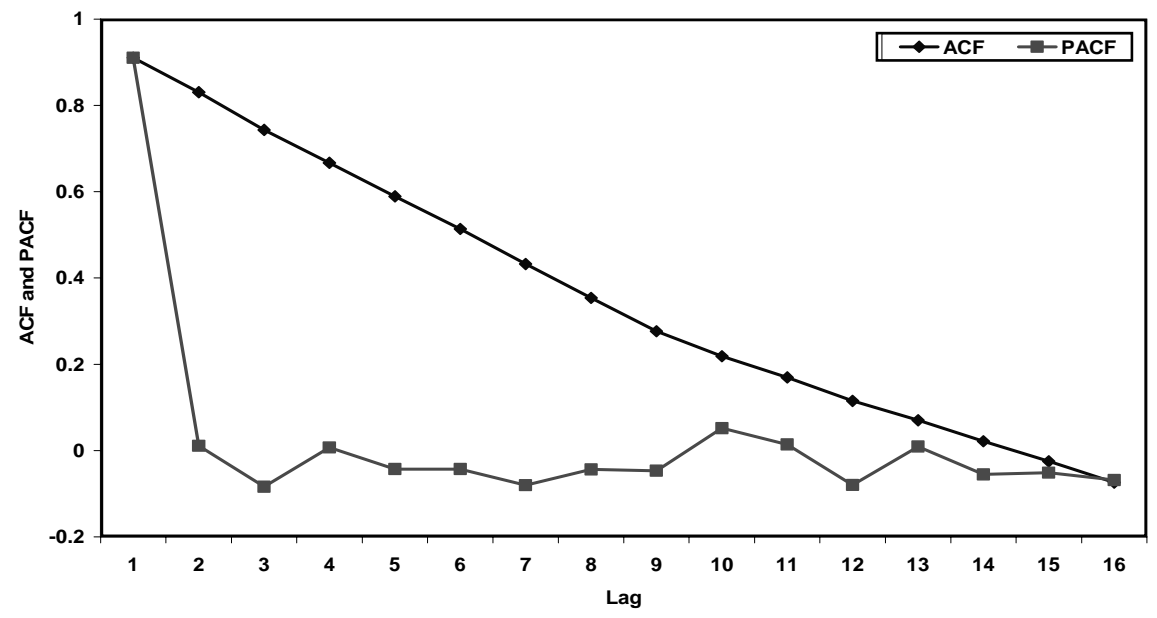

Fig. 5. Undifferenced total boro rice production in Bangladesh

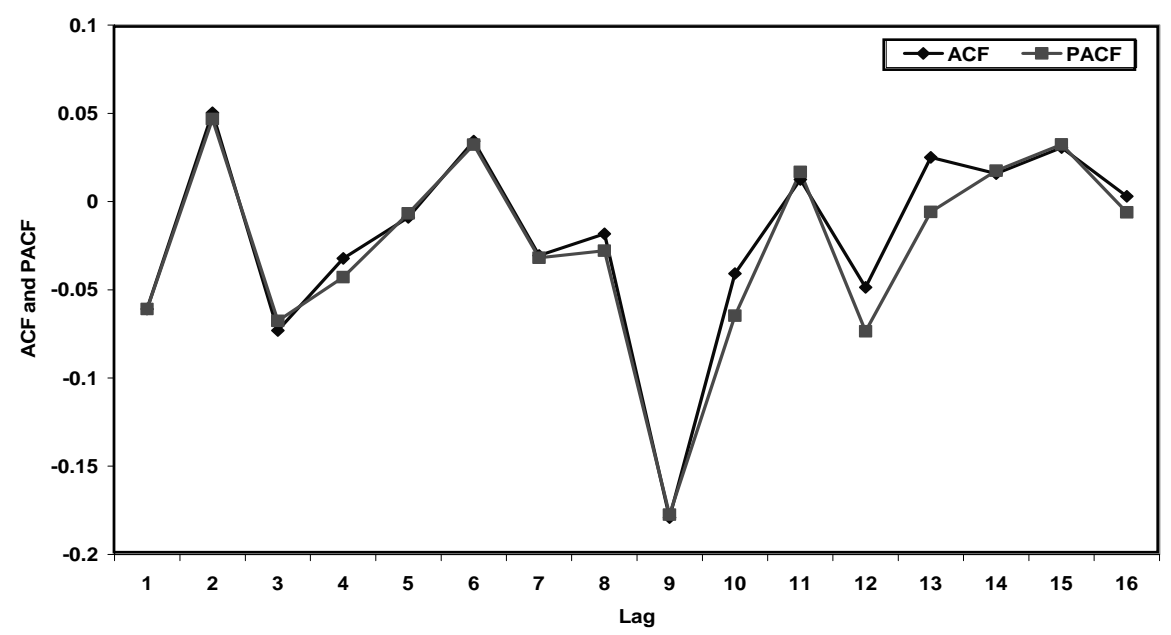

Fig. 6. 1st-differenced total boro rice production in Bangladesh 
Observing the nature of ACF and PACF plots of the series and their theoretical properties, the order of auto-regression and moving average process of local boro rice production series are selected by estimating the ARIMA models at $p=0, I$ and $q==0,1,2,3,4,5$ using the SPSS 11.5 software packages.

Twelve ARIMA models at different values of $p, d$, and $q$ are estimated using the same packages as mentioned in the previous section. The tentatively selected models are ARIMA $(0,1,0)$, ARIMA $(0,1,1)$, ARIMA $(0,1,2)$, ARIMA $(0,1,3)$, ARIMA $(0,1,4)$, ARIMA $(0,1,5)$, ARIMA $(1,1,0)$, ARIMA $(1,1,1)$, ARIMA $(1,1,2)$, ARIMA $(1,1,3)$, ARIMA $(1,1,4)$ and ARIMA $(1,1,5)$. Out of these twelve models three models are selected comparing the minimum values of the criteria $A 1 C$ and $B 1 C$. The selected models are ARIMA $(0,1,0)$, ARIMA $(0,1,1)$ and ARIMA $(1,1,0)$. These three models are again compared according to the minimum values of RMSE, MAE, MSE and MAPPE and maximum value of $R^{2}$ and $\overline{R^{2}}$ which are given in Table 3. Hence, it can be concluded that ARIMA $(0,1,0)$ is the best fitted model for forecasting the local boro rice production in Bangladesh. This justified that the selection of ARIMA $(0,1,0)$ is the best model to represent the data generating process very precisely. From the above table 3 it is observed that the model ARIMA $(0,1,0)$ is better than the other models because this model satisfied the all criterion except MSE and $\overline{R^{2}}$. So the select ARIMA $(0,1,0)$ is the best model.

Table 3. Diagnostic tools and model selection criteria for local boro rice production of best fitted models

\begin{tabular}{|c|c|c|c|c|c|c|c|c|}
\hline \multirow{2}{*}{ Model } & \multicolumn{9}{|c|}{ Values of selection criteria } & \multicolumn{1}{c|}{} \\
\cline { 2 - 9 } & MAE & MSE & RMSE & AIC & BIC & MAPPE & $\mathrm{R}^{2}$ & $\overline{R^{2}}$ \\
\hline ARIMA $(0,1,0)$ & $\mathbf{8 0 8 1 6 . 0 3}$ & $\mathbf{2 7 6 4 4 8 3 8 0 3 3 . 2 5}$ & $\mathbf{1 6 3 0 8 9 . 8 4}$ & $\mathbf{9 8 9 . 7 5}$ & $\mathbf{9 9 3 . 1 8}$ & $\mathbf{1 4 . 5 3}$ & $\mathbf{0 . 3 8 3}$ & 0.342 \\
\hline ARIMA $(0,1,1)$ & 81205.67 & $\mathbf{2 6 5 9 8 2 9 4 5 9 6 . 8 3}$ & 166267.37 & 990.17 & 995.31 & 14.74 & 0.358 & $\mathbf{0 . 3 5 0}$ \\
\hline ARIMA $(1,1,0)$ & 83408.13 & 26635915648.30 & 163205.13 & 990.23 & 995.37 & 15.08 & 0.382 & 0.349 \\
\hline
\end{tabular}

Note: The value of the criterion for a model with bold numerals that the model is better than other models with respect to that criterion

\section{Modeling time series of modern boro rice production}

For selecting ARIMA model of modern boro production series a routine test of identification applied before using Box-Jenkins methodology. Fig. 3 represents the ACF and PACF plots of modern boro rice production series at their level up to 16 lags. From this figure, the facts stand out that at the beginning ACF has nine significant spikes and PACF has only one significant spike .On the other hand, the ACF plots and PACF plots in the Fig. 4 is showing a different configuration. In this figure, the ACF shows no significant auto-correlation at any lag. It is also evident from the Box-Ljung statistic presented on the top of ACF that all the differenced values are within the $95 \%$ confidence limit. This implies that the series is non-stationary at their level and stationary at first difference. Moreover, the residuals are uncorrelated. Augmented Dickey-Fuller unit root tests are showing the stationarity position of this series at same order of difference.

Observing the nature of ACF and PACF plots of the series and their theoretical properties, the order of auto-regression and moving average process of modern boro rice production series are selected by estimating the ARIMA models at $p=0, I$ and $q==0,1,2,3,4,5,6,7,8,9$ using the same software packages.

Twenty ARIMA models at different values of $p, d$, and $q$ are estimated using the same packages as mentioned in the previous section. The tentatively selected models are ARIMA $(0,1,0)$, ARIMA $(0,1,1)$, ARIMA $(0,1,2)$, ARIMA $(0,1,3)$, ARIMA $(0,1,4)$, ARIMA $(0,1,5)$, ARIMA $(0,1,6)$, ARIMA $(0,1,7)$, ARIMA $(0,1,8)$, ARIMA $(0,1,9)$, ARIMA (1,1,0), ARIMA (1,1,1), ARIMA (1,1,2), ARIMA $(1,1,3)$, ARIMA $(1,1,4)$, ARIMA (1,1,5), ARIMA $(1,1,6)$, ARIMA $(1,1,7)$, ARIMA $(1,1,8)$ and ARIMA $(1,1,9)$. Out of these twenty models three models are selected comparing the minimum values of the criteria $A 1 C$ and $B 1 C$. The selected models are ARIMA $(0,1,0)$, ARIMA $(0,1,3)$ and ARIMA $(1,1,0)$. These three models are again compared according to the minimum values of RMSE, MAE, MSE and MAPPE and maximum value of $R^{2}$ and $\overline{R^{2}}$ which are given in Table 4 . Hence, it can be concluded that ARIMA $(0,1,3)$ is the best fitted model for forecasting the modern boro rice production in Bangladesh. This justified that the selection of ARIMA $(0,1,3)$ is the best model to represent the data generating process very precisely. 
Table 4. Diagnostic tools and model selection criteria for modern boro rice production of best fitted models

\begin{tabular}{|c|c|c|c|c|c|c|c|c|}
\hline \multirow{2}{*}{ Model } & \multicolumn{9}{|c|}{ Values of selection criteria } & AIC & BIC & MAPPE & $R^{2}$ & $\overline{R^{2}}$ \\
\cline { 2 - 9 } & MAE & MSE & RMSE & AIC & & & & \\
\hline ARIMA $(0,1,0)$ & $\mathbf{6 1 0 5 1 9 . 6 7}$ & 2516195437797.74 & 1586252.01 & 1174.70 & 1178.38 & 17.53 & 0.859 & 0.855 \\
\hline ARIMA $(0,1,3)$ & 738134.46 & $\mathbf{1 9 2 9 0 8 5 8 2 6 5 5 9 . 5 1}$ & $\mathbf{1 3 8 8 9 1 5 . 3 4}$ & $\mathbf{1 1 6 9 . 8 1}$ & $\mathbf{1 1 7 8 . 1 3}$ & $\mathbf{2 0 . 0 4}$ & $\mathbf{0 . 8 9 2}$ & $\mathbf{0 . 8 8 0}$ \\
\hline ARIMA $(1,1,0)$ & 620469.86 & 2446256761944.36 & 1564051.39 & 1175.55 & 1180.69 & $\mathbf{1 6 . 9 2}$ & 0.863 & 0.856 \\
\hline
\end{tabular}

Note: The value of the criterion for a model with bold numerals that the model is better than other models with respect to that criterion

From the above Table 4 it is observed that the model ARIMA $(0,1,3)$ is better than the other models because this model satisfied the maximum criterion except MAE and MAPPE. So the select ARIMA $(0,1,3)$ is the best model.

\section{Modeling time series of total boro rice production}

For selecting ARIMA model of total boro production series a routine test of identification applied before using Box-Jenkins methodology. Fig. 5 represents the ACF and PACF plots of total boro rice production series at their level up to 16 lags. From this figure, the facts stand out that at the beginning ACF has nine significant spikes and PACF has only one significant spike. On the other hand, the ACF plots and PACF plots in the Fig. 6 is showing a different configuration. In this figure, the ACF shows no significant autocorrelation at any lag. It is also evident from the Box-Ljung statistic presented on the top of ACF that all the differenced values are within the $95 \%$ confidence limit. This implies that the series is non-stationary at their level and stationary at first difference. Moreover, the residuals are uncorrelated. Augmented DickeyFuller unit root tests are showing the stationarity position of this series at same order of difference.

Observing the nature of ACF and PACF plots of the series and their theoretical properties, the order of auto-regression and moving average process of total boro rice production series are selected by estimating the ARIMA models at $p=0, I$ and $q==0,1,2,3,4,5,6,7,8,9$ using the SPSS same software packages.

Twenty ARIMA models at different values of $p, d$, and $q$ are estimated using the same packages as mentioned in the previous section. The tentatively selected models are ARIMA $(0,1,0)$, ARIMA $(0,1,1)$, ARIMA $(0,1,2)$, ARIMA $(0,1,3)$, ARIMA $(0,1,4)$, ARIMA $(0,1,5)$, ARIMA $(0,1,6)$, ARIMA $(0,1,7)$, ARIMA $(0,1,8)$, ARIMA $(0,1,9)$, ARIMA $(1,1,0)$, ARIMA $(1,1,1)$, ARIMA $(1,1,2)$, ARIMA $(1,1,3)$, ARIMA $(1,1,4)$, ARIMA (1,1,5), ARIMA $(1,1,6)$, ARIMA $(1,1,7)$, ARIMA $(1,1,8)$ and ARIMA $(1,1,9)$. Out of these twenty models three models are selected comparing the minimum values of the criteria $\mathrm{A} 1 \mathrm{C}$ and $\mathrm{B} 1 \mathrm{C}$. The selected models are ARIMA $(0,1,0)$, ARIMA $(0,1,2)$, and ARIMA $(1,1,0)$. These three models are again compared according to the minimum values of RMSE, MAE, MSE and MAPPE and maximum value of $R^{2}$ and $\overline{R^{2}}$ which are given in Table 5 . Hence, it can be concluded that ARIMA $(0,1,2)$ is the best fitted model for forecasting the total boro rice production in Bangladesh. This justified that the selection of ARIMA $(0,1,2)$ is the best model to represent the data generating process very precisely.

Table 5. Diagnostic tools and model selection criteria for total boro rice production of best fitted models

\begin{tabular}{|c|c|c|c|c|c|c|c|c|}
\hline \multirow{2}{*}{ Model } & \multicolumn{9}{|c|}{ Values of selection criteria } \\
\cline { 2 - 9 } & MAE & MSE & RMSE & AIC & BIC & MAPPE & $\mathrm{R}^{2}$ & $\overline{R^{2}}$ \\
\hline ARIMA(0,1,0) & $\mathbf{6 4 6 6 6 9 . 1 4}$ & 2391023609045.31 & 1546293.51 & 1172.61 & 1176.04 & 15.29 & 0.854 & 0.850 \\
\hline ARIMA(0,1,2) & 711139.58 & $\mathbf{1 9 1 5 5 7 3 0 6 0 2 8 7 . 9 3}$ & $\mathbf{1 3 8 4 0 4 2 . 2 9}$ & $\mathbf{1 1 6 7 . 5 2}$ & $\mathbf{1 1 7 4 . 3 8}$ & 17.06 & $\mathbf{0 . 8 8 3}$ & $\mathbf{0 . 8 7 4}$ \\
\hline ARIMA(1,1,0) & 647679.82 & 2314982776542.01 & 1521506.75 & 1173.29 & 1178.43 & $\mathbf{1 4 . 7 2}$ & 0.859 & 0.851 \\
\hline
\end{tabular}

Note: The value of the criterion for a model with bold numerals that the model is better than other models with respect to that criterion 
From the above Table 5 it is observed that the model ARIMA $(0,1,2)$ is better than the other models because this model satisfied the maximum criterion except MAE and MAPPE. So the select ARIMA $(0,1,2)$ is the best model.

The above discussion about the fitness of various models to the time series of boro rice production in Bangladesh reveals that $\operatorname{ARIMA}(0,1,0)$, ARIMA $(0,1,3)$ and $\operatorname{ARIMA}(0,1,2)$ models are appropriate for local, modern and total boro rice production respectively. It also reveals that the selection of the best model for a particular category can sometimes be very confusing. However the discussion recommends a best model for a particular category as given in Table 6 .

Table 6. Best estimated models for boro rice production in Bangladesh

\begin{tabular}{|l|c|l|}
\hline Variety & $\begin{array}{l}\text { The name of the } \\
\text { best model }\end{array}$ & The functional form of the model \\
\hline Local boro & ARIMA $(0,1,0)$ & $\left(\Delta Y_{t}+16720.64\right)=\varepsilon_{t}$ \\
\hline Modern boro & ARIMA $(0,1,3)$ & $\left(\Delta Y_{t}-281407.52\right)=\left(1-0.148 B+0.148 B^{2}-0.976 B^{3}\right) \varepsilon_{t}$ \\
\hline Total boro & ARIMA $(0,1,2)$ & $\left(\Delta Y_{t}-11689.94\right)=\left(1-0.189 B+0.961 B^{2}\right) \varepsilon_{t}$ \\
\hline
\end{tabular}

\section{Diagnostic checking}

For diagnostic checking ACF of residuals and Ljung and Box chi square statistic are widely used in practice. In Table 7 the chi square statistics are given for all the best-selected stochastic models with Pvalues. All the chi square values are insignificant. It implies that the residuals of the respective time series are white noise implying that the model fitness is acceptable.

Table 7. Diagnostic tools and model selection criteria for the best fitted models

\begin{tabular}{|c|c|c|c|c|c|c|c|c|c|c|}
\hline Area & Model & MAE & RMSE & AIC & $\mathrm{BIC}$ & MAPPE & $\mathrm{R}^{2}$ & $\overline{\overline{R^{2}}}$ & $\begin{array}{c}X^{2} \text { (BL at } \\
16 \text { lag) }\end{array}$ & P-value \\
\hline Local & $\begin{array}{c}\text { ARIMA } \\
(0,1,0)\end{array}$ & 80816.03 & 163089.84 & 989.75 & 993.18 & 14.53 & 0.383 & $\begin{array}{c}\text { Not } \\
\text { satisfied }\end{array}$ & 19.01 & 0.268 \\
\hline Modern & $\begin{array}{l}\text { ARIMA } \\
(0,1,3) \\
\end{array}$ & $\begin{array}{c}\text { Not } \\
\text { satisfied }\end{array}$ & 1388915.34 & 1169.81 & 1178.13 & $\begin{array}{c}\text { Not } \\
\text { satisfied }\end{array}$ & 0.892 & 0.880 & 2.82 & 1.00 \\
\hline Total & $\begin{array}{l}\text { ARIMA } \\
(0,1,2)\end{array}$ & $\begin{array}{c}\text { Not } \\
\text { satisfied }\end{array}$ & 1384042.29 & 1167.52 & 1174.38 & $\begin{array}{c}\text { Not } \\
\text { satisfied }\end{array}$ & 0.883 & 0.874 & 3.48 & 1.00 \\
\hline
\end{tabular}

\section{Forecasting}

Five years forecasts of local, modern and total boro production are estimated using the best selected models and are presented in Table 8. Prediction intervals of forecast are also presented. Table 08 reveals that the forecasted total local boro rice production in the year of 2008-09 was 193053.80 metric tons with a $95 \%$ confidence interval of $(193053.80,390211.40)$ metric tons whereas for modern and total boro rice production these values are 6401414.40 metric tons and 6594468.20 metric tons with a $95 \%$ confidence interval of $(3311872.24,9490956.56)$ metric tons and $(3311872.24,988116.96)$ metric tons respectively. The analysis found that if the present growth rates continue then the local boro rice production, modern boro rice production and total boro rice production in Bangladesh in the year of 2012-2013 will be 126171.24 metric tons, 12054627.72 metric tons and 12180798.96 metric tons with a $95 \%$ confidence interval of (126171.24, 588033.91) metric tons, (6522547.22, 17586708.22) metric tons and (6522547.22, 18174742.13) metric tons respectively. 
Table 8. Forecast of boro rice production in Bangladesh for the period of 2008-09 to 2012-13 at 95\% level

\begin{tabular}{|l|l|l|c|c|c|c|}
\hline \multirow{2}{*}{ Variety } & \multirow{2}{*}{ Description } & \multicolumn{5}{|c|}{ Forecast year } \\
\cline { 3 - 7 } & & $2008-09$ & $2009-10$ & $2010-11$ & $2011-12$ & $2012-13$ \\
\hline \multirow{2}{*}{$\begin{array}{l}\text { Local boro rice production } \\
\text { ARIMA }(0,1,0)\end{array}$} & LPL & - & - & - & - & - \\
\cline { 2 - 7 } & Forecast & 193053.80 & 176333.16 & 159612.52 & 142891.88 & 126171.24 \\
\cline { 2 - 7 } & UPL & 390211.40 & 458535.91 & 509329.29 & 551378.60 & 588033.91 \\
\hline \multirow{2}{*}{$\begin{array}{l}\text { Modern boro rice production } \\
\text { ARIMA (0,1,3) }\end{array}$} & LPL & 3311872.24 & 114370.37 & 6050215.49 & 6287137.42 & 6522547.22 \\
\cline { 2 - 7 } & Forecast & 6401414.40 & 4315717.96 & 11491812.68 & 11773220.20 & 12054627.72 \\
\cline { 2 - 7 } & UPL & 9490956.56 & 8517065.54 & 16933409.87 & 17259302.98 & 17586708.22 \\
\hline \multirow{2}{*}{$\begin{array}{l}\text { Total boro rice production } \\
\text { ARIMA (0,1,2) }\end{array}$} & LPL & 3311872.24 & 114370.37 & 6050215.49 & 6287137.42 & 6522547.22 \\
\cline { 2 - 7 } & Forecast & 6594468.20 & 4492051.12 & 11651425.20 & 11916112.08 & 12180798.96 \\
\cline { 2 - 7 } & UPL & 988116.96 & 8975601.45 & 17442739.16 & 17810681.58 & 18174742.13 \\
\hline
\end{tabular}

\section{Conclusion}

A time series model accounts for patterns in the past movement of a variable and uses that information to predict its future movements. In a sense a time series model is just a sophisticated model of extrapolation. Time series data have become very popular to be intensively used in empirical research and econometricians have recently begun to pay very careful attention to such data. To select the best model for a particular time series the latest available model selection criteria are used. The study revealed that ARIMA $(0,1,0)$, ARIMA $(0,1,3)$ and ARIMA $(0,1,2)$ models are appropriate for local, modern and total boro rice production in Bangladesh respectively and it is to be noted that the short-term forecast is better as the error of forecast increases with the increase of the period of forecast.

\section{References}

Alam, S. 1991. The Effects of Price and Non-Prices Factors on the Production of Major Crops in Bangladesh. A Thesis Submitted to the University of New Castle Upon Tyne for the Degree of Doctor of Philosophy in the Department of Agricultural Economics and Food marketing.

Bangladesh Bureau of Statistics. 2007. Statistical Yearbook of Bangladesh, Ministry of Planning, Government of the People's Republic of Bangladesh, Dhaka.

Bangladesh Bureau of Statistics. various issue (1976 to 2005). Yearbook of Agricultural Statistics of Bangladesh, Ministry of Planning, Government of the People's Republic of Bangladesh, Dhaka.

Bangladesh Bureau of Statistics. 2008. Bangladesh Economic Review. Ministry of Planning, Government of the People's Republic of Bangladesh, Dhaka.

Gujarati, D. N. (2003): Basic Econometrics. 4th edition, McGraw-Hill, Inc. New York.

Haque, M. E., Hossain, M. I. and Rahman, K. M. M. 2004. Forecasting fish production in Bangladesh using ARIMA model, J. Bangladesh Agril. Univ .3(2):381-392

Haque, M.E., Imam, M.F. and Awal, M.A.. 2006. Forecasting shrimp, frozen food export earning of Bangladesh using ARIMA model. Pakistan Journal of Biological Sciences.9(12):2318-2322.

Hossain M. 2003. Development of boro rice cultivation in Bangladesh: Trends and policies. In: Boro rice (Singh, R.K., Hossain, M. and Thakur, R. eds). IRRI-India Office. Pp 25-49.

Johnston, J.1984. Econometric Methods, Third Edition, MoGraw-Hill Inc, New York.

Koutsoyiannis, A. 1987. Theory of Econometrics. Second Edition (Low-Priced Edition), English Language Book Society, Macmillan Education Ltd, London.

Maddala, G.S. 1989. Introduction to Econometrics. Macmillan Publishing Company, New York, 223-226. 
Pindyck, R.S. and Rubinfeld, D.L. 1998. Econometric Models and Econometric Forecasts. 4th ed. McGraw-Hill, Boston, Massachusetts Burr Ridge, Illinois Dubuque, lowa Madison, Wisconsin New York, New York San Francisco, California St. Louis, Missouri.

Razzaque, M.A. 2000. Annual Report 1998-99. Lentil, Blackgram, Mungbean Development Pilot Project, Bangladesh Agricultural research Institute. Joydebpur, Gazipur, Bangladesh.

Singh, P.K., Hossain, M. and Thakur, R. 2003a. In: Boro rice (RK Singh, M Hossain and R Thakur, eds). IRRI-India Office.

Singh, R.K., Thakur, R. and S.D. Chatarjee. 2003b. Harnessing boro rice potential for increasing rice production in deepwater areas of Eastern India, An overview. In: Boro rice (RK Singh, M Hossain and R Thakur, eds). IRRI-India Office. Pp. 51-72.

Thakur R, Singh, N.K. and Chaudhary, V.K. 2003. Recent advances in boro rice research in Bihar. In: Boro rice (RK Singh, M Hossain and R Thakur, eds). IRRI-India Office. Pp. 99-116. 